\title{
ORAL ROTE SEQUENCING ABILITIES OF KINDERGARTEN AND FOURTH-GRADE STUDENTS
}

\author{
NANCY WILSON \\ Windsor Western Hospital Centre \\ Windsor, Ontario, Canada \\ RALPH R. RUPP \\ The University of Michigan \\ Ann Arbor, Michigan
}

\begin{abstract}
A population of 300 Kindergarteners and fourth graders were asked to perform a series of rote sequencing language tasks which included naming the days of the week, the months of the year, saying the alphabet and counting. The subjects were also asked to name as many colors as they could. Provisional norms for the performance on these tasks were proposed from the data. The data suggest no difference in performance between the sexes in either grade population. Marked improvement in rote sequencing abilities appeared for all tasks between the two grade levels except for naming colors.
\end{abstract}

Kass (1972) states that an automatism is "an act performed without reflection or intent, often without realizing that it has taken place." Based on this statement, automatic speech may be defined as the production of a speech segment which is so well learned that it may be produced without putting much, if any, thought into it. In the context of this study, the term "rote sequencing" is used synonymously with "automatic speech." The word "rote" suggests learning to the point of memorization. Common language sequences are the focus of the study.

The question which was initially intended to be addressed was whether the rote sequencing abilities of children may be an indication of the child's auditory perceptual integrity. This question is based on the possibility that such sequencing abilities are related to auditory memory. Very little has been written in the area of rote sequencing, although it is often used as part of an evaluation of the language abilities of individuals such as aphasics. One example of this is the Boston Diagnostic Aphasia Examination 
(Goodglass and Kaplan, 1972). This test examines the subject's ability to recite the days, months, alphabet, and numbers in the proper order, among other things. However, most individuals taking this test are adults who have lost intact language functioning, rather than children who have not yet acquired a mature language structure. Other studies, such as the one by Seeck (1934), look at rote memory, but use nonsense syllables as stimuli. In such instances, short term memory is assessed, rather than language structures which have been embedded in the long term memory of the subject.

In order to discover whether the rote sequencing abilities of children are in fact related to their auditory perceptual integrity, it is necessary to look at the relationship between this and the normality of the child's rote sequencing abilities. A literature search did not reveal the ready availability of such norms.

In the Utah Test of Language Development, Mecham, Jex and Jones (1967) maintain that at age five a child should be able to name colors. However, no mention is made of how many colors the child should be able to name. Fairchild and Thomas (1976) state that as a pre-kindergarten educational program objective, the preschool child should be able to name the days of the week in sequence $100 \%$ of the time. However, no study was cited to indicate that it is normal for children in this age group to be able to perform such a task. Several clinicians in the Children's Division and Aphasia Division at the University of Michigan Speech and Hearing Sciences Section knew of no norms at all pertaining to the rote sequencing abilities of children. Although it is recognized that the listing of colors is not a sequencing task, it is included in this study as a point of interest. An uncited norm in an informal paper on child development (anonymous, undated, a), maintained that at 42 months of age, a child should be able to name all of the colors. However, no indication was given of what constituted "all the colors." In contrast, another uncited norm in a different informal paper on child development (anonymous, undated,b), stated that at age five, a child should know four colors.

It seems that if norms exist, they are not readily available to speech and language clinicians. Therefore, in order to investigate the possibility that a child's ability to perform rote sequencing of common serials is an indication of auditory perceptual integrity, it is first appropriate to develop such norms to be made available for use in the clinical setting. The purpose of this study was to develop provisional norms for children at the kindergarten and fourth grade level. 


\section{METHOD}

\section{Subjects}

This study was performed in a small semi-rural community in southeastern Michigan. The subject was members of the lower middle socioeconomic classes. One hundred and forty-nine children in their sixth month of kindergarten and 151 children in their sixth month of fourth grade served as subjects. In the kindergarten group, 80 were males and 69 females. The age range of this population was 5-6 years. In the fourth grade group, 79 were males and 72 were females. The age range of this population was 9-11 years. All subjects passed a school hearing screening test presented at $20 \mathrm{~dB} \mathrm{HL}$ at octave frequencies from 500 to $8000 \mathrm{~Hz}$ immediately prior to participation in the study.

\section{Apparatus}

The only special equipment required was a score sheet, on which the experimenter recorded the responses and personal data of each subject.

\section{Procedure}

Prior to starting the data gathering, notations were made on the child's age, grade and sex. The experimenter began by asking the subject, "Can you name the days of the week?" If the subject responded by naming the days of the week, the response was recorded. If the subject responded with "yes," the experimenter said, "Please name them," and the response was recorded. If the subject stated that he could not name the days of the seek, he was prompted with "Sunday" and his response was recorded with the notation that it was prompted. The same procedures were followed when the experimenter presented the subjects with the following stimuli: "Can you name the months of the year?" employing "January" as the prompt if necessary; "Can you say the alphabet?" "A" used as the prompt if needed; "Can you count?" employing "one" as the prompt when needed; and "Can you name the colors?" using different colors as the prompt in each case requiring it. In the counting task, if a kindergarten subject asked how high he should count, he was told to count as high as he could, and was stopped at 39. If a fourth grade subject asked how high to count, he was told to count to 50 . If he did not ask, he was stopped at 50, if he counted that high. In the colors task, if the subject paused for five seconds after naming a color, he was not allowed to proceed further with the task. It must be pointed out that the colors in the test environment were not controlled factors. Therefore, in the color responses, the subject may have been aided 
by looking at colors in the environment.

The tasks were presented in the same order as listed above, to each subject.

\section{Scoring}

The subject's score for each task was the number of items which he named in the proper sequence, without skipping any items. In the day listing task, the subject was required to begin his sequence with "Saturday, Sunday, or Monday." This allowed for environmental differences which may cause the subject to believe the week to begin on a day other than Sunday, without giving him credit for a sequence which he began with a day which is obviously in the middle of the week. In the month listing task, the subject was required to begin the sequence with "January" to be considered correct. Similarly, in the alphabet task, the child was expected to begin with " $A$ ", and in the counting task, he was required to begin with "one." In the color naming task, the subject was permitted to begin with any color, since this is not a sequential task. However, note was made on which color the child began and the number of colors named. (Crayola Corporation identifies 72 colors.)

It was decided, as a procedure, that if a child paused for five seconds, a prompt was required. While such prompted responses were recorded, they were not tabulated into the results. It was decided that if a child required prompting, his response was not automatic.

\section{RESULTS}

The mean, median, range, and standard deviation were calculated for males, females, and both sexes pooled together, in each grade level, for each task, as reported in Table I.

\section{Days of the Week}

For the days listing task, scores are in units representing the number of days named in correct sequence. The mean for kindergarten females was 1.6. For kindergarten males, and kindergarten subjects pooled, the mean was 1.7. For fourth grade females the mean was 6.7 days. Male fourth grade subjects produced a mean of 6.5 , and the mean for fourth grade subjects pooled was 6.6 days. The difference between pooled mean scores was 4.9 days.

Of 149 kindergarten subjects, 96 did not perform the day listing task at all, whereas 23 subjects in that group named all days of the week in the correct sequence. Of 151 fourth graders, three did not 
Table 1. Performance results for rote sequencing expressed in mean, median, range and standard deviation values for each task and population.

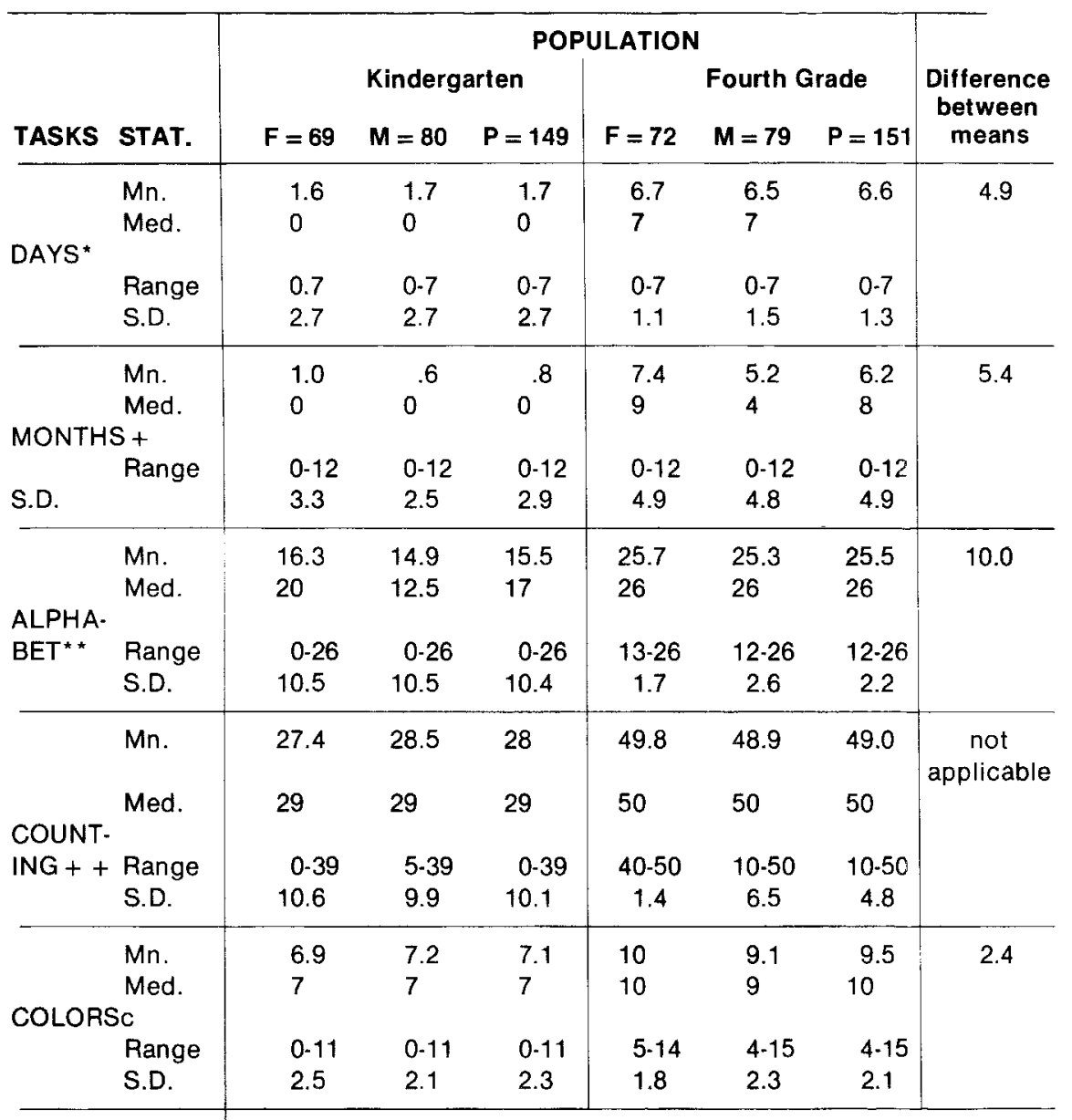

*units are number of days in order; + units are number of months in order; ${ }^{*}$ units are number of letters in order; ++ units are highest number counted to; $c$ units are number of colors named.

perform the task at all, but 135 were able to perform it with complete accuracy.

\section{Months of the Year}

In the months listing task, scores are in units representing the number of months named in the proper order. For kindergarten females, the mean was 1.0. Kindergarten males scored a mean of .6 months. The mean was .8 when all kindergarten scores were pooled. The mean was 7.4 for fourth grade females, 5.2 for fourth 
grade males, and 6.2 for fourth grade subjects, pooled. The difference between pooled mean scores was 5.2 months.

It was observed that 135 kindergarten subjects did not perform the month listing task at all. Seven of the subjects correctly sequenced all 12 months. In the fourth grade group, 41 subjects did not correctly sequence any months, and 44 performed the task completely accurately.

\section{Repeating the Alphabet}

In the alphabet task, scores are in units representing the number of letters named in the correct sequence. In this task, the mean was 16.3, for kindergarten females, 14.9, for kindergarten males, and 15.5 , for kindergarten subjects pooled. In the fourth grade category, the females scored a mean of 25.7 letters. The males scored a mean of 25.3 letters. When males and females were pooled, the mean was 25.5 letters. The difference between pooled mean scores was 10 letters.

Twenty five of 149 kindergarteners did not perform the alphabet task at all, but 65 gave the whole alphabet correctly. In the fourth grade group, 142 of 151 subjects said the entire alphabet correctly. There was not one fourth grade subject who did not at least begin the alphabet correctly.

\section{Counting}

In the counting task, the scores represent the highest number counted to correctly. In the kindergarten group, the females scored a mean of 27.4 numbers. The males scored produced a mean of 28.5 numbers. When pooled, the mean was 28 numbers. In the fourth grade group, the mean was 49.8 numbers for females, 48.9 numbers for males and 49.0 numbers for this group, pooled. The differences are not reported since the assignments to the two groups were not the same.

Forty seven of all kindergarten subjects counted all the way to the limit imposed by the experimenter. Two kindergarten subjects did not begin to count in the correct sequence. In the fourth grade group, all subjects at least began the task, and 141 counted to the limit imposed by the experimenter.

\section{Color Naming}

In the color naming task, scores represent the number of colors named. In the kindergarten group, the mean was 6.9 colors for females, 7.2 colors for males, and 7.1 colors for the group pooled. In the fourth grade group, the females scored a mean of 10 colors, the males scored a mean of 9.1 colors, and the fourth graders 
pooled scored a mean of 9.5 colors. The differences between pooled mean scores was 2.4 colors.

When all 300 subjects were pooled, red was the overwhelming favorite color to be named first, with 132 subjects using it to begin their color list. Blue was second, with 44 subjects employing it first, and green and purple tied for the third most favorite, with each color being used by 23 subjects to begin their lists. There was not a larger proportion of these colors in the test environment than others to account for their frequent use.

\section{DISCUSSION}

These results indicate that in all tasks, male and female kindergarten means fell within one standard deviation of each other, suggesting that the average female and average male kindergarten student do not have appreciably different rote sequencing abilities on these tasks. The same holds true in the fourth grade group.

For all tasks, the mean scores of the kindergarten females fell at least one standard deviation below the mean scores of females in the fourth grade. The same is true for the day listing, alphabet and counting tasks for kindergarten boys. This suggests that for these groups, and under all conditions for females, and those listed above for males, with the exception of the counting tasks, noticeable improvement in task performance is made in the four years of education between kindergarten and fourth grade. Such conclusions cannot be drawn about the counting tasks because the standards were different. In the month and color listing tasks, the mean of kindergarten males fell within the first standard deviation of the mean of fourth grade boys. While the fourth grade males scored higher on their tasks than those in kindergarten, the data suggest that the four years of education between groups do not cause as noticeable an improvement as can be seen for other tasks, and in the female group.

Looking at the pooled scores for each task and grade level, the kindergarten subjects' means fell at least one standard deviation below the fourth grade mean in the day listing, month listing, alphabet and counting task, keeping in mind the double standard on the counting task. This again suggests that the four years of development make a difference in performance for the tasks. In the colors task, the groups fell within one standard deviation of each other. The four years of development do not cause as big an improvement in this task as in others, possibly due to the fact that colors are not listed sequentially, or that colors are a very early learned task. 
Many subjects' responses fell at $\mathrm{N}$-maximum and/or $\mathrm{N}$-minimum with relatively few subjects distributed in between in many cases. This suggests that subjects frequently knew either none of the sequence or the whole thing. This emphasized the importance of automatism in these sequences. Often, if the subject could begin the sequence, then he had enough cueing to complete it. One exception is in the fourth grade responses in the month listing task. There is an accumulation of scores at the N-9 entry. This indicated that in some instances the subjects correctly began the sequence but could not complete it, and October was the month most often skipped or the cause for confusion in the sequence. Also, the accumulation of responses at $\mathrm{N}$-minimum and/or $\mathrm{N}$ maximum does not occur in the case of the color listing task. In this case, the accumulation fell at approximately the mean. This may be attributed to the fact that color listing is not a serial task.

Other observations made during the course of the study merit mention. Many of the children who had difficulty listing the months were asked if they could say in which month their birthday fell. Of the 78 fourth graders asked, $80 \%$ answered by giving the name of a month (veracity of the response was not questioned). However, of the 133 kindergarteners asked, only $2.8 \%$ responded in the same manner. The same children who were having problems with "months" were also asked if they could say in which month the Fourth of July fell. All of the fourth graders who were asked this question responded with a month or month and day. Among the kindergarten subjects asked, only $47.6 \%$ gave such a response. Those who answered incorrectly gave responses such as "Easter time," "Easter Bunny day." "After Christmas," "when we moved," "long time," and "same as my brother's". The kindergarten subjects' responses to these two questions may indicate that these subjects are aware of the cyclical nature of the year, but they do not seem to understand what a month is.

In the alphabet task, track was kept of how many children employed the alphabet "song" or the song's rhythm in their attempt to say the alphabet. As a point of interest, $27.5 \%$ of the kindergarteners used the song, and $20.8 \%$ used the rhythm. In the fourth grade group, however, only $5.3 \%$ used the song, while $29.8 \%$ used rhythm in attempting to say the alphabet.

Based on the results of this study, norms are proposed for the rote sequencing of days, months, alphabet, counting, and the name of colors. The mean scores suggest the central tendancy of the findings, the standard deviations suggest the magnitude of the variability of the responses for the two age-related populations. 
Based on this study, for children in about their sixth month of kindergarten, the average response for the day sequencing task is 1.7 days, for the month sequences task the normal response is .8 months; for the alphabet task the normal response is 15.5 letters; for the counting task the normal response is $\mathbf{2 8}$ out of a possible 39; and for the colors naming task, the normal response is 7.1 colors. For children in about their sixth month of fourth grade, the normal response for the day sequencing task is 6.6 days; for the month naming task the normal response is 6.2 months; for the alphabet task the normal response is 25.5 letters; for the counting task the normal response is 49 out of a possible 50; and for the color naming task, the normal response is 9.5 colors.

This study could lead the way for future research. One such area of study would be to develop norms for children at other levels of education. Another route would be to discover whether children performing within the norms on these tasks also produce normal responses on auditory perception and processing batteries, and whether those who perform below the norms also perform below the norms on auditory perception and processing batteries.

\section{REFERENCES}

Fairchild, L., and Thomas, C., "A Public Schools Subcommittee Report: Samples of Performance Objective Formats," Michigan Speech and Hearing Association Journal, 12)2), (1976).

Goodglass, H., and Kaplan, H., "Boston Diagnostic Aphasia Examination", in Assessment of Aphasia and Related Disorders, Philadelphia, Lea and Febiger, (1972).

Kass, C., "Educational Management of Reading Deficits" in Irwin, J. V., and Marge, M., Principles of Childhood Language Disabilities, Englewood Cliffs, New Jersey, Prentice-Hall, Inc., (1972).

Mecham, M. J., Jex, J. L., and Jones, J. D., The Utah Test of Language Development, Salt Lake City, Communication Research Associates, (1967).

Seeck, G. C., Form of the Curve of Memory in Rote Learning.(dissertation) University of Michigan, Microfilm 3321, Pub. \#21,507, (1934). 